\title{
EFEITOS DE FILTROS DE Poncirus trifoliata E DE ALTURAS DE ENXERTIA NA LARANJEIRA VALENCIA ENXERTADA EM LIMÃO-CRAVO
}

\author{
V.R. SAMPAIO \\ Departamento de Horticultura - ESALQ/USP, C.P. 9, CEP: 14418-900 - Piracicaba,SP
}

\begin{abstract}
RESUMO: Foram estudados os efeitos de filtros de Poncirus trifoliata $(5-10-20 \mathrm{~cm})$ e de variações nas alturas de enxertia (15-25-35 cm) para a combinação laranjeira Valencia sobre Limão-cravo. $O$ experimento implantado a 28/11/84 teve sua avaliação final realizada em outubro de 1992 e permitiu as seguintes conclusões: 1) 0 emprego de filtros de Poncirus trifoliata resultou em redução no tamanho das plantas; provocou atraso no início de frutificação e menores produções de frutos; 2) Dentro dos limites estudados, as variações nas extensões dos filtros e nas alturas de enxertia não afetaram o desenvolvimento e as produções das plantas.
\end{abstract}

Descritores: citrus, filtro, alturas de enxertia, laranja Valência

\section{EFFECTS OF Poncirus trifoliata INTERSTOCKS AND BUDDING IIGITT OF VALENCIA ORANGE ON RANGPUR LIME ROOTSTOCK}

\begin{abstract}
ARSTRACT: Effects of Poncirus trifoliata interstocks $(5-10-20 \mathrm{~cm})$ and budding hights $(15-25-35 \mathrm{~cm})$ were studied for Valencia orange on Rangpur lime rootstock. The trial, carried out from 1984 to 1992 , led to the following conclusions: 1) insertion of Poncirus trifoliata interstocks resulted in reduction of plant size, production precocity and yield; 2) vegetative development and yield of valencia orange plants were not affected by different budding highs and by Poncirus trifoliata interstock extension.
\end{abstract}

Key Words: citrus, interstock, budding height, Valencia orange

\section{INTRODUÇÃO}

A inserção de um tecido diferente entre a copa e o porta-enxerto, na constituição de uma planta, pode acontecer intencionalmente por ação do viveirista, ou por vezes como solução adotada pelo produtor ao fazer a mudança de copas em pomares já instalados.

Segundo BITTERS et al. (1981 a), estes filtros, usualmente provocam pequenas alterações na fisiologia da planta, pois os maiores efeitos são exercidos pelos porta-enxertos. O emprego de filtros merece especial atenção nos casos de ocorrência de doenças de virus e para contornar efeitos de incompatibilidade localizada. De acordo com HARTMANN \& KESTER (1983) existem várias razões para o emprego da dupla enxertia na propagação de plantas. Uma delas seria o de contornar os efeitos de incompatibilidade, outra é a possibilidade do filtro possuir característica não existente na copa, nem no porta-enxerto, a qual o faz de importante no todo. Terceira razão para o emprego da dupla enxertia é quando o filtro pode ter influência no desenvolvimento da planta.
Existem interessantes pesquisas com macieiras (Malus domestica) e pereiras (Pyrus spp) relacionadas ao emprego de dupla enxertia. Para macieiras ROBERTS \& BLANEY (1967), fizeram confronto bibliográfico e relataram influências recíprocas quando do uso das combinações entre os porta-enxertos 'EM IX' e 'EM XVI' e a copa 'Starking Delicious'. Usando os porta-enxertos, ora como tal, ora como filtros e neste caso empregando variadas extensões dos mesmos e alternando as alturas de enxertia, chegaram as seguintes conclusões: a) a influência dominante era do tecido da raiz, fato esse em concordância com a pesquisa bibliográfica realizada; b) os filtros alteraram os desenvolvimentos das plantas, e no caso particular do 'EM IX' houve indução à floração precoce sendo que esta resposta foi proporcional à dimensão do filtro; c) a posição do filtro alterou o desenvolvimento das plantas, assim o filtro de 'EM IX' colocado baixo no tronco, reduziu o seu tamanho.

As pesquisas de duplas enxertias com pereiras referem-se predominantemente à tentativa de obter melhor compatibilidade da copa com os porta-enxertos, via de regra, marmeleiros (Cydonia oblonga). Assim temos os trabalhos de LUPESCU 
(1970), GUR et al. (1978) e LENZ \& BRAUN (1987), onde ficaram patentes os efeitos diferenciados dos filtros sobre a produção, vigor e a longevidade das plantas.

Em citros, BITTERS et al. (1981a e 1981b) pesquisando os efeitos de dupla enxertia, usaram copa de 'Valencia' e porta-enxertos de tangerineira 'Cleopatra' e citrange 'Troyer', assim como filtros destes mesmos materiais reciprocamente. Fazendo variações no posicionamento e na extensão destes filtros, concluiram que filtros de 'Troyer' com $15 \mathrm{~cm}$, inseridos a $15 \mathrm{~cm}$ de altura, resultaram em plantas com maiores produções. Inserções mais altas dos filtros $(30$ e $40 \mathrm{~cm}$ ) resultaram em menores produções. Verificaram também que as plantas com filtros apresentaram menores volumes e produções levemente inferiores, quando comparadas as plantas sem filtros. Fazendo variações nos tamanhos dos filtros $(5,15$, 30,45 e $60 \mathrm{~cm}$ ) inseridos sempre a mesma altura de $15 \mathrm{~cm}$, ocorreram copas maiores para plantas portadoras de filtros $c o m 15 \mathrm{~cm}$ de extensão. No mesmo trabalho, fazendo-se uso de filtros de 'Cleopatra', verificou-se que aqueles com $15 \mathrm{~cm}$ de extensão, quando colocados à diferentes alturas propiciaram maiores produções quando inseridos a $30 \mathrm{~cm}$. As maiores plantas foram aquelas com inscrção dos filtros a $5 \mathrm{~cm}$ e não a $15 \mathrm{~cm}$, como ocorreu para o 'Troyer'. Plantas com filtros tiveram produções e volumes menores do que aquelas sem filtros, ou seja cerca de metade da produção e dois terços do tamanho.

De acordo com BITTERS et al. (1981a) e SAMPAIO (1990) o emprego de filtros em plantas cítricas não determinou variações nas características dos frutos. Já LLORENTE et al. (1984) verificaram variações no teor de acidez, comprimento dos frutos e espessura da casca do limão 'Verna', enxertado em laranja 'Azeda', por influência de filtros de cultivares de laranjas doces. Os teores de nutrientes das folhas da laranja 'Valencia' não sofreram variações em função do emprego de filtros, conforme relato de LABANAUKAS \& BITTERS (1974) e SAMPAIO (1990).

Segundo instrução normativa do Ministério da Agricultura, a muda cítrica deve ter o enxerto realizado, entre dez e vinte centímetros de altura. Esta orientação está de acordo com as recomendações dos técnicos, como é possível verificar nos trabalhos de MOREIRA \& RODRIGUES (1960), SALIBE (1969) e TEÓFILO SOBRINHO (1991).
De acordo com BITTERS et al. (1981 b) a altura ótima para enxertia das plantas cítricas, visando melhor comportamento no pomar, não foi ainda estabelecida. As alturas empregadas dizem mais respeito à tradição e conveniência dos viveiristas. $\mathrm{Na}$ revisão feita por estes autores, ficou evidenciada que a altura de enxertia influencia o comportamento da planta cítrica. Esta constatação é corroborada pelos trabalhos de MURRAY (1951), BITTERS et al. (1981 a) MOREIRA et al. (1981) e SAMPAIO (no prelo), com a informação de que enxertias mais altas resultam $\mathrm{cm}$ menores plantas e produções. Ainda segundo BITTERS et al. (1981 a), a altura crítica da enxertia, o ponto de virada, situar-se-ia a cerca de trinta centímetros.

$O$ objetivo primordial do trabalho aqui apresentado, foi o de estudar os efeitos dos filtros de Poncirus trifoliata, sobre o desenvolvimento vegetativo e a produção da laranjeira Valencia enxertada em Limão-cravo. Como o emprego de variadas extensões de filtros redundou em diferentes alturas finais de enxertia, foram utilizados no experimento, tratamentos com enxertias simples à alturas correspondentes, para determinar possiveis interferências deste fator.

\section{MATERIAL E MÉTODOS}

O experimento foi realizado no Departamento de Horticultura da Escola Superior de Agricultura Luiz de Queiroz. As mudas cítricas foram obtidas a partir de semeação realizada em maio de 1982, sendo as enxertias realizadas a $03 / 08 / 83$ e $10 / 11 / 83$. Na primeira data praticou-se a enxertia com borbulhas de Poncirus trifoliata, cv. Mexicano, material proveniente da Estação Experimental de Citricultura de Cordeirópolis. Esta primeira enxertia realizada a quinze centímetros de altura, buscou a formação dos filtros. Na segunda data foram feitas as enxertias de todas as plantas experimentais com borbulhas de laranja Valencia, provenientes de coleção do Departamento de Horticultura. Os diferentes procedimentos nas formações das mudas, resultaram nos seis tratamentos experimentais:

T1 - Dupla enxertia. Filtro de Poncirus trifoliata com cinco centímetros de extensão.

T2 - Dupla enxertia. Filtro de Poncirus trifoliata com dez centímetros de extensão.

T3 - Dupla enxertia. Filtro de Poncirus trifoliata com vinte centímetros de extensão. 
T4 - Enxertia simples a quinze centímetros do solo. T5 - Enxertia simples a vinte e cinco centímetros do solo.

T6 - Enxertia simples a trinta e cinco centímetros do solo.

O plantio experimental ocorreu a 28/11/84 onde os tratamentos com quatro repetições foram esquematizados no delineamento em blocos ao acaso, com emprego de duas plantas por parcela. As mudas de torrão foram implantadas em solo classificado como latossolo vermelho série Luiz de Queiroz.

Foram dispensados ao experimento tratos culturais adequados. $O$ fornecimento de nutrientes obedeceu orientação de análises de solo. Nos anos de 1988 e 89, aplicou-se calcário dolomítico à razão de uma e meia tonelada por hectare em cada oportunidade. Nos períodos críticos fez-se irrigações e o controle do mato foi realizado pela combinação de aplicação do herbicida glyfosate na linha de plantas e roçagem no restante da área. Até a presente data nenhuma planta foi danificada por quaisquer razões.

Para avaliação do experimento acompanhou-se o desenvolvimento das plantas através de mensurações das alturas e diâmetros médios das copas e circunferências dos troncos, sendo estas últimas praticadas a quarenta centímetros do solo. Os volumes das copas foram calculados pela fórmula $\mathrm{V}={ }^{2} /{ }_{3} \pi \mathrm{R}^{2} \mathrm{H}$, fórmula essa utilizada por POMPEU Jr. (1972) e outros pesquisadores. As produções foram quantificadas anualmente. Os dados foram analisados estatisticamente utilizando-se o teste de Tukey para confronto das médias.

\section{RESULTADOS E DISCUSSÃO}

\section{1) Desenvolvimento das plantas}

Os valores resultantes das medições, realizadas em março de 1992, dos vários parâmetros utilizados para aquilatar os desenvolvimentos das plantas estão na TABELA 1 .

$O$ exame da TABELA 1 permite concluir que o emprego de filtros de Poncirus trifoliata provocou alterações no desenvolvimento das plantas cítricas. Variações nas extensões dos filtros assim como nas alturas de enxertia, dentro dos limites estudados, não afetaram este mesmo desenvolvimento. Estes resultados que aparentemente contrariam aqueles relatados pelos pesquisadores citados no capítulo Introdução, teriam explicação na pequena variação nos tamanhos dos filtros $(5-10-20 \mathrm{~cm})$, assim como na altura máxima empregada, que foi de trinta e cinco centímetros. Os autores relatados trabalharam em níveis bem superiores, detectando diferenças entre os tratamentos. Alterações ocorreram para os parâmetros circunferênciais dos troncos, alturas e volumes das copas. Para circunferências dos troncos, parâmetro esse que expressa o desenvolvimento global das plantas verifica-se que os tratamentos com enxertia simples resultaram superiores e diferentes dos tratamentos portadores de filtros, com exceção única para o confronto dos tratamentos quatro e dois. Resultados semelhantes aconteceram no estudo das alturas e volumes das copas de 'Valencia', cujos valores submetidos a análise mostraram-se idênticos. Assim nota-se que o tratamento cinco não diferiu dos demais tratamentos que receberam enxertia simples, porém resultou em plantas mais altas e mais volumosas no confronto com aquelas portadoras de filtros (tratamentos um, dois e três). Também o tratamento seis foi diferente dos tratamentos um e três, o mesmo acontecendo no confronto dos tratamentos quatro e três. Os resultados encontrados deixam patente a influência da presença dos filtros de $P$. trifoliata, independente de suas extensões, no desenvolvimento vegetativo das copas de 'Valencia' enxertadas cm Limãocravo.

Estes resultados tem apoio nos trabalhos de BITTERS (1981a e 1981b) no que concerne à presença, ou ausência de filtros nas plantas cítricas. Certa discrepância existe quanto as extensões dos filtros, onde aqueles autores encontraram influência das mesmas. É importante porém reforçar a informação de que os referidos pesquisadores trabalharam com extensões bem maiores de filtros.

\section{2) Produçāo de frutos}

O experimento implantado a $28 / 11 / 84$ iniciou produção em 1987. As quantificações das várias colheitas estão expressas na TABELA 2.

Constata-se que plantas resultantes da enxertia simples tenderam a maior precocidade de produção. Para a produção acumulada no período 1987-89, encontra-se que os tratamentos quatro e seis tiveram produções superiores no confronto com os tratamentos portadores de filtros. Também o tratamento cinco apresentou maior produção comparativamente ao tratamento três. 
TABELA 1 - Médias das circunferências dos troncos, alturas, diâmetros e volumes das copas de laranjeiras Valência, com oito anos de idade, enxertadas em Limão-cravo, com variações nas alturas de enxertia e emprego de filtros de Poncirus trifoliata. Piracicaba 1992.

\begin{tabular}{lllll}
\hline \hline Tratamentos & $\begin{array}{l}\text { Circunferências } \\
\text { dos troncos }(\mathrm{cm})\end{array}$ & $\begin{array}{c}\text { Alturas das copas } \\
(\mathrm{m})\end{array}$ & $\begin{array}{l}\text { Diâmetros das } \\
\text { copas }(\mathrm{m})\end{array}$ & $\begin{array}{l}\text { Volumes das } \\
\text { copas }\left(\mathrm{m}^{3}\right)\end{array}$ \\
\hline 1-Filtro $5 \mathrm{~cm}$ & $35.70 \mathrm{c}$ & $3.14 \mathrm{~cd}$ & $2.99 \mathrm{a}$ & $14.81 \mathrm{~cd}$ \\
2-Filtro $10 \mathrm{~cm}$ & $36.41 \mathrm{bc}$ & $3.28 \mathrm{bcd}$ & $3.07 \mathrm{a}$ & $16.20 \mathrm{bcd}$ \\
3-Filtro $20 \mathrm{~cm}$ & $33.66 \mathrm{c}$ & $3.05 \mathrm{~d}$ & $2.95 \mathrm{a}$ & $13.98 \mathrm{~d}$ \\
4-Enxertia $15 \mathrm{~cm}$ & $40.27 \mathrm{ab}$ & $3.57 \mathrm{abc}$ & $3.31 \mathrm{a}$ & $20.47 \mathrm{abc}$ \\
5-Enxertia $25 \mathrm{~cm}$ & $43.26 \mathrm{a}$ & $3.77 \mathrm{a}$ & $3.40 \mathrm{a}$ & $22.96 \mathrm{a}$ \\
6-Enxertia $35 \mathrm{~cm}$ & $44.71 \mathrm{a}$ & $3.71 \mathrm{ab}$ & $3.31 \mathrm{a}$ & $21.32 \mathrm{ab}$ \\
\hline \hline
\end{tabular}

TABELA 2 - Produções médias de frutos de laranjeiras Valencia, enxertadas em Limão-cravo com variações nas alturas de enxertia e emprego de filtros de Poncirus trifoliata, Piracicaba 1992.

\begin{tabular}{|c|c|c|c|c|c|c|c|c|}
\hline \multirow[b]{2}{*}{ Tratamentos } & \multicolumn{6}{|c|}{ Números médios de frutos por planta } & \multicolumn{2}{|c|}{$\begin{array}{c}\text { Prod. Acumuladas } \\
\text { períodos }\end{array}$} \\
\hline & 1987 & 1988 & 1989 & 1990 & 1991 & 1992 & $1987-89$ & $1987-92$ \\
\hline Filtro $5 \mathrm{~cm}$ & $10,6 \mathrm{~b}$ & $121,6 \mathrm{ab}$ & $198,6 \mathrm{a}$ & $416,9 \mathrm{a}$ & $485,2 a$ & $394,1 \mathrm{a}$ & $33,1 \mathrm{bc}$ & $3251,5 \mathrm{bc}$ \\
\hline Filtro $10 \mathrm{~cm}$ & $12,0 \mathrm{~b}$ & 97,5 ab & $205,2 a$ & $426,7 \mathrm{a}$ & $479,2 a$ & $477,6 a$ & $314,7 \mathrm{bc}$ & $3391,1 \mathrm{abc}$ \\
\hline Filtro $20 \mathrm{~cm}$ & $12,6 \mathrm{~b}$ & $91,1 \mathrm{~b}$ & $176,6 \mathrm{a}$ & $392,0 \mathrm{a}$ & $489,4 a$ & $409,4 a$ & $280,4 c$ & $3124,2 \mathrm{c}$ \\
\hline Enxertia $15 \mathrm{~cm}$ & $38,7 \mathrm{ab}$ & $184,0 \mathrm{a}$ & $219,0 \mathrm{a}$ & $447,6 \mathrm{a}$ & $608,0 \mathrm{a}$ & $554,0 \mathrm{a}$ & $441,6 a$ & $4103,3 \mathrm{ab}$ \\
\hline Enxertia $25 \mathrm{~cm}$ & $38,5 \mathrm{ab}$ & $148,0 \mathrm{ab}$ & $246,5 \mathrm{a}$ & $513,6 a$ & $570,9 \mathrm{a}$ & $557,7 \mathrm{a}$ & $433,0 \mathrm{ab}$ & $4142,4 a b$ \\
\hline Enxertia $35 \mathrm{~cm}$ & $51,4 a$ & $166,2 \mathrm{ab}$ & $245,1 \mathrm{a}$ & $483,0 \mathrm{a}$ & $587,5 \mathrm{a}$ & $572,8 a$ & $462,7 \mathrm{a}$ & $4201,8 \mathrm{a}$ \\
\hline
\end{tabular}

Para a produção acumulada no período $1987-92$, todos os tratamentos com enxertia simples superaram as produções das plantas do tratamento três, assim como o tratamento seis mostrou também maior produção em relação ao tratamento um.

Verifica-se ainda que os tratamentos por enxertias simples resultaram em maiores produções de frutos em todas as colheitas no confronto com os tratamentos com plantas portadoras de filtros. Embora nem sempre essas diferenças tenham sido detectadas pela análise da variância, nota-se uma tendência, que fica mais explícita na observação das produções acumuladas no período 1987-92, onde é dado a verificar que as plantas obtidas por enxertia simples produziram em média um total de quatro a cinco caixas a mais que as plantas portadoras de filtros. Este efeito da presença dos filtros na produção das plantas cítricas é concordante com aquele relatado por BITTERS et al. (1981 e 1981b).

Observa-se ainda que as diferentes extensões de filtros e alturas de enxertia não alteraram as produções de frutos da laranjeira Valencia enxertada em Limão-cravo. A explicação para estes resultados é idêntica àquela já feita $\mathrm{em}$ relação ao desenvolvimento vegetativo das plantas. Constatou-se pois que os níveis de extensões dos filtros e das alturas de enxertia foram insuficientes 
para alterar as produções das plantas, no confronto entre essas variações. Isto posto, não existe contradição com a literatura citada.

\section{CONCLUSÕES}

1- O emprego de filtros de Poncirus trifoliata na combinação laranjeira Valencia sobre Limão-cravo resultou em redução no tamanho das plantas. provocou atraso no início da frutificação e menor produção de frutos.

2- Dentro dos lımites estudados, as variaçòes nas extensões dos filtros de Poncirus trifoliata e as diferentes alturas de enxertia não afetaram o desenvolvimento e a produção da laranjeira Valencia enxertada em Limão-cravo.

\section{REFERÊNCIAS BIBLIOGRÁFICAS}

BITTERS, W.P.; COLE. D.A.; MCCARTY, C.C. Effect of budding height on yield and tree size of 'Valencia' orange on two rootstock. Proceedings of the International Society of Citriculture. Riverside, v.1. p.109-110, 1981 .

BITTERS, W.P.: COLE, D.A.: MCCARTY, C.C. Effect of height and lenght of reciprocal interstock insertion on yield and tree size of 'Valencia' orange. Proceedings of the International Society of Citriculture. Riverside, v.1, p.110-113, 1981.

GUR, A.; ZAMET, D.: ARAD. E. A pear rootstock trial in Israel. Scientiae Ilorticulturae. Amsterdan, v.8, n.3, p.249-264. 1978.

HARTMANN, H.T.; KESTER, D. Plant propagation. 4.ed. Englewood Cliffs: principles and practices. New Prentice Hall, 1983. 727p.

LABANAUKAS, C.K.; BITTER. W.P. The influence of rootstocks and interstocks on the nutrients levels in 'Valencia' orange leaves. Joumal of the America Society for Horticultural Science, Alexandria, v.99, p.32-33. 1974.

LENZ, F.; BRAUN, P. Effect of rootstock and cultivar selection as well as interstock on the growth and yield of pears cultivars. Erwerbsobstbau. Bonn, v.29, n.8, p.243-244, 1987. Bonn, Apud HORTICULTURAL ABSTRACTS, E. Malling, v.59, n.4, p.2689. 1989.

LLORENTE, S.; ROMOJARO, F.; UREÑA, R.; ALCARAZ, C.F. Influence of intermediate grafting tecnique on Verna lemon fruit quality. In: VI INTERNATIONAL COLLOQUIUM FOR THE OPTMIZATION OF PLANT NUTRITION, 6., 1984, Montpelier. Proceedings... Montpellier: GERDAT, 1984. v.1, p.339-344.

LUPESCU, F. The effect of the interstock on the growth and fruiting of pear trees varieties. Bucharest: Scientific Institutal Agronomic, 1970, v.13, p.177-179. Apud HORTICULTURAL ABSTRACTS. East Malling, v.42, n.1, p.557, 1972.

MOREIRA, S.; RODRIGUES FILHO, A.J. Cultura dos Citros. São Paulo: Melhoramentos, 1960. 120p.

MOREIRA, C.S.; RODRIGUEZ, O.: POMPEU JUNIOR, J.; TEÓFILO SOBRINHO, G.; SALIBE, A.A. The effect of budding heights on tree size of Citrus trees affected by exocortis viroid. Proceedings of the International Society of Citriculture. Riverside, v.1, p.148-149, 1981.

MURRAY, D.B. Citrus experiments at the St. Augustine Experiment Station. Tropical Agriculture. Trinidad, v.28, p.215-217, 1951 .

ROBERTS, A.N.; BLANEY, L.T. Qualitative, quantitative and positional aspects of interstock influence on growth and flowering of the apple. Proceedings of the American Society for Horticultural Science, Alexandria, v.91, p.39-50. 1967.

SALIBE, A.A. Curso de especializaçāo em citricultura a nível de pós-graduaçāo. Recife: SUDENE, 1969. $176 \mathrm{p}$.

SAMPAIO, V.R. Behaviour of 'Valencia' orange trees grafted on Rangpur lime with interstock of Poncirus irifoliata. In: INTERNATIONAL HORTICULTURAL CONGRESS, 23., Firenze, Abstracts... Bologna: National Research Council, 1990. p.329.

SAMPAIO, V.R. Comportamento da laranjeira Piralima sobre Poncirus trifoliata com variaçōes na altura de enxertia. Scientia Agricola. Piracicaba v.51, n.1, 1994. (no prelo).

TEÓFILO SOBRINHO, J. Propagação dos citros. In: RODRIGUEZ, O.; VIEGAS, F.; POMPEU JUNIOR, J.; AMARO, A.A. Citricultura Brasileira. Campinas, Fundação Cargill, 1991. v.1. p.281-301.

Enviado para publicação em 14.06 .93

Aceito para publicação em 10.09.93 